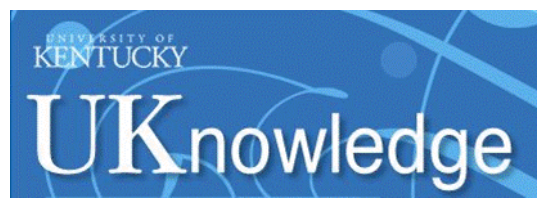

University of Kentucky

UKnowledge

\title{
What Documents Cannot Do: Revisiting Michael Polanyi and the Tacit Knowledge Dilemma
}

C. Sean Burns

University of Kentucky, sean.burns@uky.edu

Follow this and additional works at: https://uknowledge.uky.edu/slis_facpub

Part of the Epistemology Commons, Philosophy of Science Commons, and the Scholarly

Communication Commons

Right click to open a feedback form in a new tab to let us know how this document benefits you.

\section{Repository Citation}

Burns, C. Sean, "What Documents Cannot Do: Revisiting Michael Polanyi and the Tacit Knowledge Dilemma" (2021). Information Science Faculty Publications. 77.

https://uknowledge.uky.edu/slis_facpub/77

This Article is brought to you for free and open access by the Information Science at UKnowledge. It has been accepted for inclusion in Information Science Faculty Publications by an authorized administrator of UKnowledge. For more information, please contact UKnowledge@lsv.uky.edu. 


\title{
What Documents Cannot Do: Revisiting Michael Polanyi and the Tacit Knowledge Dilemma
}

\author{
Digital Object Identifier (DOI) \\ https://doi.org/10.7560/IC56104
}

\section{Notes/Citation Information}

Published in Information \& Culture, v. 56, issue 1.

This is a pre-copyedited version of an article accepted for publication in Information \& Culture 56 , issue 1 , (2021) following peer review. The definitive publisher-authenticated version is available from University of Texas Press.

The copyright holder has granted the permission for posting the article here. 
This is a pre-copyedited version of an article accepted for publication in Information \& Culture 56, no. 1 (2021) following peer review. The definitive publisher-authenticated version is available from University of Texas Press.

\title{
What Documents Cannot Do; Revisiting Polanyi and the Tacit Knowledge Dilemma \\ C. Sean Burns
}

\section{Running Header: What Documents Cannot Do}

Bio: C. Sean Burns is an associate professor of information science at the University of Kentucky. His research areas include scholarly communication, information retrieval, and the history of automation. He holds a PhD in information science and learning technologies from the University of Missouri.

\begin{abstract}
Our culture is dominated by digital documents in ways that are easy to overlook. These documents have changed our worldviews about science and have raised our expectations of them as tools for knowledge justification. This paper explores the complexities surrounding the digital document by revisiting Michael Polanyi’s theory of tacit knowledge - the idea that "we can know more than we can tell." The theory presents to us a dilemma: if we can know more than we can tell, then this means that the communication of science via the document as a primary form of telling will always be incomplete. This dilemma presents significant challenges to the open science movement.
\end{abstract}

Keywords: tacit knowledge, Michael Polanyi, documentation, philosophy of science, open science 
The wonderful thing about metaphors is that they often hide in plain sight, and this is true whether they are everyday kinds of metaphors or the kinds of metaphors that we use in scientific writing or analysis. For example, the digital document presented to us in an office word processor application as a sheet of paper is a graphical metaphor of a physical sheet of paper (otherwise referred to as a skeuomorphism); that is, it is a conceptual mapping (i.e., the metaphor) expressed graphically as well as linguistically (i.e., its "metaphorical expression"). ${ }^{1} \mathrm{I}$ was reminded of both the power and the frailty of this metaphor recently when I observed a young child use word processor software for the first time. The child, wanting to use a computer to write a story about a dragon and a giant, knew how to write, relative to their age, but the near entirety of their textual experience had been with physical paper. They were familiar with others reading to them from paper books, reading from paper books themselves, and drawing and learning to write on physical paper. Thus, on their first introduction to word processor software, they apparently seemed comfortable with the image of a physical sheet of paper that was presented to them.

However, as the child pressed keys to write something, the metaphor of the sheet of paper began to crumple. I had not anticipated this when I introduced them to the software. For me (as a long-time user of these types of programs), these issues with the software and the system surrounding it had become seamless by use, if not by design. ${ }^{2}$ The child's questions reminded me of how accustomed I had become to the interface that I had forgotten the kinds of issues their questions raised. Here are a few of the issues that arose - all because of the loss of integrity of the paper metaphor:

1. Upon initial use, the child assumed that they could write anywhere on the page, as they often do when using physical sheets of paper and did not understand at first why they were restricted to the top left of the page.

2. The child had to learn how to manipulate the cursor to create empty, editable space on the page, even though what they were presented with appeared to be empty, editable space: i.e., a blank sheet of paper.

3. The child noticed the page indicator on the bottom of the application window after having created four pages of text of various colors, sizes, and font types, and they had navigated to page three when they noticed it, which informed them that they were on 
page 3 of 4 . The child concluded that it was unfortunate that they only had four pages to use. They had inferred that page 3 of 4 meant that four was the maximum number of sheets available to them.

4. Spell checking was turned on, and the child noted the red squiggly lines that appeared under misspelled words. When I told the child what those lines meant, the child altered their behavior. Instead of simply writing and playing with the text, the child began to switch modes - write, edit, write, edit. This became a distraction and a source of worry, which the child did not have before.

I do not know if the above experience will end up as an important memory for the child, but it was important to me, not just as someone who knows and cares deeply about this person but also as a someone interested in the kinds of things, such as metaphors, that hide in plain sight yet may influence our behaviors, relationships, beliefs, and knowledge. This is true not only for those common, everyday kinds of metaphors but also the ones we use in our more rigorous areas of experience, such as in the sciences.

In the child's case, the graphical metaphor expressed as a sheet of paper served as a source of confusion and obstruction, but in the sciences, metaphors are often intentionally, if not always successfully, conceived and employed to enlighten rather than to obstruct or confuse. ${ }^{3}$ The philosopher of science Susan Haack wrote that "while some scientific metaphors are more decorative than functional, others suggest questions to investigate, directions in which to look," regardless whether those directions may lead us astray or to fruitful lines of inquiry. ${ }^{4}$ If Haack is correct, then it seems appropriate to ask about the origins of those metaphors that are used in the sciences — of things like "black hole," "superbugs," "food chains," and "invisible hand," or problematic ones, like "sleeping beauty," all of which are intended to provide a special sort of "epistemic access." 5

It is certainly the case that metaphors in science may arise out of popular culture and from literature of any genre, which is also where good philosophical and theoretical thinking can be found. Nathaniel Hawthorne's short story, "Earth's Holocaust," could be said to offer a theory that locates the source of moral problems not in institutions, literature, art, and epistemologies but in human nature itself, and his story therefore criticizes our attempts to fix the world (by burning everything) without addressing that nature first. ${ }^{6}$ If theory is a collection of 
interdependent propositions that explain something about the world (biological or social or the like), where propositions are statements that express something meant to be true, then surely literature can include such statements, even if the goal of literature is neither to explain nor predict nor classify but, as is sometimes the function of art, to foster understanding, inspire wonder or critique, express rage or love, or highlight injustice. We might derive from Hawthorne's story some important theoretical insight about the emptiness of our revolutionary motivations, as a result, without first looking inward at other probable causes. Metaphor, then, can be used not only to point the way, as Haack noted, but also to forge scientific theories and to learn how to ask good questions. As the philosopher Richard Boyd argued:

There exists an important class of metaphors which play a role in the development and articulation of theories in relatively mature sciences. Their function is a sort of catachresis - that is, they are used to introduce theoretical terminology where none previously existed.... Indeed, their users are typically unable to precisely specify the relevant respects of similarity or analogy, and the utility of these metaphors in theory change crucially depends upon this open-endedness. ${ }^{7}$

It seems helpful to ask if a substitution is true, too. If scientists use metaphors such as "worm holes," "black holes," "electron clouds," and "the cloud" to constitute, build, and communicate theories, then surely artists use metaphors to make propositions that likewise function as a theory of some part of reality. This should be true even if the propositions are embedded within dialogue, analogies, allusions, tropes, or allegories. For instance, in one part of Don DeLillo's 1985 novel, White Noise, we find the protagonist waiting at the airport with his ex-wife for the arrival of their daughter. As they wait and passengers disembark a newly arrived plane, an exiting passenger stops to recount a harrowing story about a sudden, steep drop in the plane's altitude. When the protagonist's daughter finally appears, she says, in reference to the tale:

\footnotetext{
"Where's the media?" she said.

"There is no media in Iron City."

"They went through all that for nothing?"8
} 
This simple exchange between two characters in a novel expresses a kind of general, propositional truth about our media-enriched social world (or social-enriched media world) and captures a postmodern concept that has gained theoretical traction in the intervening decades as the ability to document and disseminate has scaled - another metaphorical term - along with the growth of the web; as Leonard Wilcox observes, a work like "White Noise suggests such moments of authentic and unfettered subjectivity are being supplanted by a Baudrillardian euphoria or 'schizophrenia' which characterises the experience of the self in the space of the simulacrum." In today's parlance, this is reflected in the "pics or it didn't happen" meme: a requirement that the transmission through a media, the simulacrum, provides the necessary condition for the self's existence as if our substantiality necessarily depends upon that media. ${ }^{10}$

So here we are-we have gone from a simple facsimile of a sheet of paper that functions as an inadequate graphical metaphor to the necessary existence of the document, likely presented via some metaphorical abstraction and disseminated as media to justify a proposition. More succinctly, these may be stated as theses:

\section{Thesis 1: The digital document is a (inadequate) metaphor.}

Thesis 2: This (inadequate) metaphor necessarily provides the justification to know a proposition (that something is true) about reality.

This is not to say that the "pics or didn't happen" concept is a good theory about the possibility of postmodern truth about self-hood. Video footage, i.e., documentation, can be contested and re-interpreted. When footage or documentation is contested, opposing sides form to contest the facts of the case that have been captured on video or in phone call transcripts. ${ }^{11}$ In such cases, the accused work diligently to find a way out or an alternate interpretation (or "narrative," to use a post-academic, trending term), in order to negate what has been recordedto argue that the real was not fully documented and therefore what was documented was not fully real. That aside, the point is that art and literature and music and other non-scientific genres can provide important theoretical insights. And it can be good to appreciate art when it is capable of doing this kind of work. Rebecca Solnit's 2013 The Faraway Nearby is one such example but in the form of a kind of memoir and reflection on topics including age, illness, frailty, family, and 
more. ${ }^{12}$ The Faraway Nearby begins with a delivery of apricots from Solnit's mother's tree that, over time, begin to ripen and decay as they lay on her bedroom floor. Some of the apricots are eventually used to make jam but some rot because of Solnit's indecision. These motifs of worth, change, and decay appear throughout the memoir.

Of course, there may be as many takeaways from this memoir as there are readers. This is part of the beauty of art, that it can mean something different depending on who we are or where we are in our lives but still provide insight into the fundamental aspects of reality that we all share. Arnold Hauser, a sociologist and art historian, provides a description of this shared purpose of art and science:

A work of art is not "correct" or "incorrect" in the way a scientific theory is; it cannot properly speaking be termed either true or false. The concept of changeless, superhistorical validity can be applied to art only with very special reservations, and here all talk of "false consciousness," as of correct consciousness, is out of place. In other words: when truth is not what is aimed at, it is idle to speak of conformity to it or evasion of it. Art is partisan through and through, and because a view of reality which did not reflect any particular standpoint would be devoid of all artistic quality, the problem of relativity simply does not arise in art. Every aspect of art is a perspective; only one that involves an inner contradiction can rightly be termed "false."

And yet it would be wrong to deny to art all claim of achieving truth, to deny that it can make a valuable contribution to our knowledge of the world and of man. That works of literature are an abundant source of knowledge requires perhaps no further proof; the most penetrating achievements of psychological insight which we have at our disposal derive from the masters of novel and drama. But there can be no doubt that the visual arts also contribute a good deal toward giving us our bearings in the world. It is, of course, important to point out the difference between scientific knowledge and artistic representation, to emphasize, for instance, that to speak "stylistic" trends is perfectly legitimate in art, but very questionable in science. The sociologist, however, can only feel uneasy about any too radical separation of art and science. For after all, the worldview of a generation - or, more exactly, of a group that is historically and socially selfcontained - is an indivisible whole. Attempts to demarcate the different fields in which 
this world-view manifests itself may be very promising from the epistemological point of view, but to the sociologist they appear as violent dissections of the reality he studies. To him, philosophy, science, law, custom, and art are different aspects of one unitary attitude to reality: in all these forms men are searching for an answer to the same question, for a solution to one and the same problem of how to live. They are not ultimately concerned with formulating scientific truths, producing works of art, or even laying down moral precepts, but with achieving a workable world-view, a reliable guiding principle for life. Always and everywhere they are bent upon one and the same task, that of subjugating the bewildering strangeness and ambiguity of things. ${ }^{13}$

So, art is not like science, but is. In the latter, the goal is to come to a consensus on meaning and facts, but there are parts of the artistic endeavor, subjective as they may be, that do theoretical work, and as a researcher of things related to documentation and information and libraries, I find that it is partly my task to note those things, just as I had noted and was taken aback by the personal rediscovery of a word processor document as a metaphorical sheet of physical paper.

One particular passage from Solnit's work struck me in this way, in that, beyond the specifics, it suggested something meaningful and theoretical about the relationship between geography, environment, and recorded knowledge, of which belief is a prerequisite of the latter. Solnit wrote:

Years ago I visited a friend who lived on a houseboat and while admiring the lemon trees and prickly pears flourishing ferociously in half-barrel planters on his deck was told that the deck was forever rotting away from the dampness and had to be replaced at least once a decade. As we walked down the long plank boardwalk back to shore, we talked about whether humidity and aridity themselves could have been forces that shaped religious belief. There are in many damp places a belief in reincarnation, the eternal renewing of life and the world, which of course also means eternal dying. In the warm, damp regions everything disintegrates, regenerates, must be rebuilt, manuscripts must be copied over as the pages decay, and the air is full of spores and bacterias and insects eager to consume and transmute. 
In the dry world you can at least fantasize about unchanging permanence and eternity, and bodies can be mummified, preserved for drying — like fruit, fish, books in libraries, the Dead Sea scrolls, and paintings in climate-controlled museums. In the cold world things may also last for ages, like the frozen bodies of mammoths and mountaineers. ${ }^{14}$

When I read that, I thought of the following theoretical propositions, not necessarily condoned here, but just there, implicitly suggested in the text:

1) Documents are sensitive to their environments.

A) If the environment is polar or arid, documents last longer and have a chance for permanency.

B) If the environment is tropical, documents are more susceptible to decay.

2) Our beliefs about the world are shaped by the condition of our documents.

A) If documents tend toward permanency, then the content of our beliefs have a permanence to them - a being-ness to them.

B) If documents are more subject to decay, that is to say, to change, then the content of our beliefs might have a becoming-ness to them.

I like this idea about the relation between the document and the environment and how the particulars of that relationship might have an influence on our beliefs and actions over time. ${ }^{15}$ There was once a time when we were very concerned with this relationship - when the main focus was on printed works stored on, for example, library shelves. As a reminder, I suggest reading the 1932 The Library Quarterly article that reports damage caused by bookworms and fungus and offers tested solutions to these issues by way of controlling humidity and temperature. ${ }^{16}$ Despite this, it is true that I may have taken more from Solnit's passage than she had intended, but this is art that she has given us, and it is permitted of me to draw meaning from it in my own way. Artistic warrant offers more latitude than scientific warrant does, perhaps. However, since I have formulated it as a proto-theory, even if I never set out to test it, I might be predisposed to such a theory because of my context and because it points to interesting implications. The main one, in my mind, is a consideration of what happens when we detach the 
document from direct physical interaction and map its content to a concept (conceptual mapping: the definition of metaphor) that, although still possessing a materiality (its storage), it is not a materiality of the paper-in-hand kind. ${ }^{17}$ The end result is that the document's primary existence is no longer subject to the kinds of damage that worried previous generations, such as mold, beetles, or foxing, and it no longer possesses an odor, even if it may succumb to other kinds of damage when stored on physical items such as optical media or the like. ${ }^{18}$ (To test the theory, I might hypothesize that the architecture of recently built academic libraries conforms to these changes in technology and their use and thus include more windows because they collect and store fewer physical works [sunlight can damage books] and thus may avoid the concerns with preserving those physical works? The academic library becomes shaped by the decline in the need to preserve paper-in-hand items due to a rise in the use of devices that display documents conceptually.) It is such considerations that might lead us to ask that if the environmental context of the document has an effect on our beliefs, then what happens to our beliefs when the document becomes even more conceptually abstracted away from our natural environment? When its environment changes? When it is mapped to the digital? Therefore:

Thesis 3: The digital document, as a conceptual mapping (metaphor) that has a digital environment abstracted from a reference point, influences the world-view of the surrounding culture.

The shortcoming with the theory derived from Solnit is that perhaps our beliefs became fixed (anchored) when we moved away from primarily oral traditions to written ones, as Walter Ong proposed - when the document became the gravitational center of our beliefs regardless of its relative immunity to its surroundings. ${ }^{19}$ Then it is the case that our beliefs vary around the document (holding it fixed), which, regardless of the document's susceptibility to the environment, is perhaps more stable than any kind of oral tradition can possibly be. But now that the document in its digital existence itself varies in form and presentation, then it must be the case that these two things vary: beliefs and documents. As the philosopher David Suda noted, quoting Walter Ong, "the written alphabet elicits an 'overwhelming' sense of control by immobilizing the unidirectional flow of time." ${ }^{20}$ In an offline world, we might have looked to that "unvarying text" for a sense of stability, as the author Larry McMurtry does when motivated 
to re-read. ${ }^{21}$ But today, writing and the written alphabet themselves are both mobile, and in their hastened flux, make understanding our beliefs all that much more complicated.

So the document and its form and presentation influence our beliefs (and certainly the other way around - but the goal here is to reflect on the one direction for now). The crux of this is that belief is a necessary but insufficient component of knowledge. When philosophers write about epistemology, they write about how we know things and how we provide justification so that we may know, and quite a bit of this epistemological work is spent on a certain kind of knowledge. This knowledge is the kind of knowledge that we articulate (make explicit) when we say a thing propositionally, like, "I know that the planet Earth is largely spherical in shape." Propositional knowledge is also sometimes referred to as know-that knowledge and is often structured in a particularly grammatical way to aid demonstration and analysis: e.g., S knows that $\mathrm{P}$, or a Subject knows that a Proposition. ${ }^{22}$

Knowledge, under the justified true belief (JTB) view, states that we can only know $\mathrm{P}$ if it is true (T) and not false, we can only know $\mathrm{P}$ if we believe (B) $\mathrm{P}$ and not if we do not believe $\mathrm{P}$, and we can only know $\mathrm{P}$ if we have justification $(\mathrm{J})$ in believing $\mathrm{P}$ and not otherwise, such as by luck. ${ }^{23}$ If these conditions are sufficiently met, then we have knowledge of the know-that type. For example, if we fail to meet the condition of belief that the planet Earth is largely spherical in shape (i.e., we do not believe that the planet Earth is largely spherical in shape), then we do not carry that knowledge around with us (e.g., flat earthers may know that people believe that the Earth is largely spherical in shape, but since they themselves do not believe it, they do not know it). Or, that is knowledge we do not have, even if it is true, even if there is justification for it, and even if we are aware that such a proposition has been made by others (we might believe they are lying to us or that their justification is faulty).

The issue is that justification, under the everyday view, largely comes by way of the document, as recorded testimony, like when we read a report of a science experiment. If the document has become a digitally-based metaphorical expression of the paper-in-hand kind, if text is in a state of flux, then this has implications for knowledge of the know-that type.

One way that the condition of the digital document has reshaped beliefs and also attitudes is reflected in the open science and open access movements, each of which use metaphors with the term "open," a term that, while useful and illustrative, hardly captures the theoretical and applied complexities involved. When the internet and later the web made the storage and 
dissemination of scientific documents possible at a different scale and with fewer physical distribution restrictions, the new affordances that became available because of the interdependence of these technologies changed expectations and also beliefs about the way scientific communication ought to function and also the way science ought to be conducted. ${ }^{24}$ Therefore:

\section{Thesis 4: We have placed a greater burden on the document to provide justification.}

We demand much from the document. Since, most of the time, we cannot watch, interact, participate, or study in other people's labs, on their computers, or with them in their fieldwork as they conduct scientific investigations and experiments, we have depended on the scientist's ability to report about the processes, environments, and methods used when investigating and experimenting. As a result, science, and especially its replicability, depends on good scientific communication, and good scientific communication now depends on documenting the entire workflow-i.e., the steps, materials, and other activities and qualities that are a part of that process (and also on writing well). ${ }^{25}$ Although this has long been true, the expectations for documentation, from the document, have only increased. In the past, when science was offline, it was perhaps sufficient to publish a report of an experiment or a study, but now there is a growing expectation, and a growing industry, to publish a reproducible work flow, to make the research (or lab) notes, software code and scripts, data and and other items publicly available and thus depict in the documentation the know-how process of knowledge production. ${ }^{26}$ This has likewise added a burden on the scientist as well as on the infrastructure that supports scientific communication, like libraries.

Michael Polanyi's claim that "we can know more than we can tell"-what he refers to as tacit knowledge — raises additional dilemmas. ${ }^{27}$ The "tacit" here can sometimes be read and used per its common usage, as something that is simply not articulated in words or speech, or as "implicit assumptions" or as things "taken-for-granted." 28 But these conceptualizations undervalue the epistemological barrier to, per Polanyi, articulate or codify know-how knowledge. In short, the theory takes a strong epistemological stance when it posits that we can know more than we can tell, even if there is disagreement about the type of knowledge that may always remain tacit and the type of knowledge that has the potential to be explicit but has not yet 
become so or that we have not figured out how to make so. ${ }^{29}$ Some problems we face with tacit knowledge, with this knowing more than telling problem, is whether tacit knowledge can be made explicit (can it be codified as know-that knowledge, or information?). ${ }^{30}$ If so, is it tacit knowledge rather than just implicit in some way; is it the case that there will always be some kind of knowledge that will forever resist documentation; and whether, among other things, is it worth documenting, or attempting to document, certain kinds of tacit or implicit knowledge, because, for example, the cost is high in some important way or the cognitive load of too much documentation is burdensome (e.g., information overload)? Case in point: I highly doubt anyone has learned to ride a bike by reading an instruction manual. However, what if we wanted to train a robot to ride a bike? Then it would be necessary to codify the process, make explicit some kind of know-how knowledge by converting it into some kind of know-that knowledge, with respect to the affordances appropriated to the robot and its programming.

Epistemological transparency is not a new issue for science. Historians and sociologists of science have written about early motivations to publicize, review, and disseminate scientific reporting, ${ }^{31}$ and Robert Merton's insights about the norms of science touch on the communal aspect of this issue. However, what is interesting as of late is that web and internet technologies have rekindled the debate primarily because these technologies, as they have evolved, provide an enhanced ability to document, in more detail and in more thoroughness, a greater part of the scientific process - Latour's "science-in-the-making" aspect and not just the "ready-made science"-in a spirit of since it can be done, then do it approach, which is not a rational justification for such an action. ${ }^{32}$ The assumption is that more and better information and documentation of the scientific process - the workflow and not merely the reported methods and findings - the argument goes, will lead to a better way of doing science (across all domains within it), and a more reliable science. Stated otherwise, it is suggested that the move represents a migration from the "matter of fact" mode of science, to the "matter of proof" mode, where more epistemic weight is placed on the scientific (writ-large) workflow and not just on the perceived facts that dominate what is communicated in the research report. ${ }^{33}$

These assumptions, however, need testing. First, the same epistemological questions raised above apply to scientific workflow documentation as they do to the scientific reportwhat do scientists know more than they can tell in the process of doing scientific research? How much of and of what kind of their tacit knowledge needs to be made explicit, if it can be? If some 
tacit knowledge cannot be made explicit, does this type of knowledge present any true obstacles to reproducibility that avoids the Gettier problem, where we might achieve reproducibility not by luck but by true justification? ${ }^{34}$

Once those epistemological questions are surveyed, then the assumptions about the communication and practice of science need to be addressed. For example, is the quality of the scientific enterprise a function of its epistemological transparency - its openness and the openness of its various aspects? How important are some of these composite parts of science in its epistemological goal: open science, open access, open source, open standards, open peer review? What are the upper and lower bounds of this function? Or, if science is a function of transparency in knowledge production made possible by documentation, what are the lower and upper bounds of the kind of epistemological transparency needed for a healthy scientific enterprise? How much tacit must be made explicit? It turns out that these problems hold true across the spectrum of organized human activity and not just the scientific enterprise if we follow Susan Haack's view that scientific knowledge is not epistemologically privileged but simply more rigorously formed than everyday knowledge. ${ }^{35}$

It is these challenges that make the tacit knowledge problem interesting for our state of affairs. In his first lecture in The Tacit Dimension, Polanyi articulates four aspects of tacit knowing: functional, phenomenal, semantic, and ontological. The functional aspect lays out how we know a thing tacitly. Specifically, we know a thing tacitly by attending to some related, explicit thing. His example: people who are given electrical shocks when presented with certain nonsense syllables know when to expect the shocks even when they cannot say what specific nonsense syllables are triggering the shocks. They attend to the shocks and, by attending to them, attend from the particulars that cause them (the nonsense syllables). The particulars become known in this attending from. How else, Polanyi argues, would subjects in this test know when to expect the corresponding shocks? But even though the subjects tacitly know the particular nonsense syllables that trigger the shocks, they can not tell so explicitly since they know more than they can tell.

The particulars are often difficult to parse. There is a tendency, sometimes, to reduce wholes to their parts (the particulars) when explaining the wholes. We see this kind of thing when some scientists or philosophers seek to reduce human consciousness to a kind of physical location in the brain. ${ }^{36}$ This kind of thinking has extraordinary implications, for if all higher 
order things (e.g., people) can be reduced to their lower level, basic physical parts (i.e., the wholes are merely summative of the physical aspects that comprise them), then all problems at the whole can be addressed simply by attending to the parts, especially the tangible, mechanistic parts. For example, can all mental health issues be addressed simply by attending to the physical processes or components in the brain, or, to borrow an example from Polanyi, can we fix someone's grammar simply by fixing that person's vocabulary since the grammar of a language is simply made up of its parts, the words and their forms? And then, can we attend to someone's style of writing simply by attending to that person's grammar, and so on?

This reductionist way of explaining things by lieu of their physical components (and of viewing the world, i.e., defining reality or what is real [the ontological]) was a hallmark of positivism and has been common across all domains of knowledge and areas of practice. Several years ago I was doing historical work at an institutional archive and reading annual library reports from around the mid-twentieth century. ${ }^{37}$ One of the common problems that the head librarian described in those reports concerned the university administration's view of the library as nothing more than a warehouse of books. As the head librarian, Ralph Parker, described it, the administration at his institution ignored (or even failed to see) the complexities attached to managing and using a library and, as a result, repeatedly failed to invest in the library and the librarians who operated it (the practical implication of a reductionist viewpoint). For the librarian, the library was more than a warehouse of books; in the process of acquiring, describing, managing, shelving, circulating, and using the works in the library, and the library itself, something greater emerged or came into existence that was beyond a basic warehouse. And the thing that emerged was as real as any of its constitutive parts (e.g., books and shelves), even if it could not be reduced to those parts. Thus, even though the administration would agree that the library was a real place, it was only real to them as the "cobblestones" of the street are real - as opposed to whole streets with their social worlds and other components (the whole is reduced to a part that then becomes its perceived entire ontological substance; perhaps we can think of this as synecdochic fallacy ${ }^{38}$ ). However, per Polanyi, this is a failure to recognize emergence:

This capacity of a thing to reveal itself in unexpected ways in the future I attribute to the fact that the thing observed is an aspect of a reality, possessing a significance that is not 
exhausted by our conception of any single aspect of it.... And since I regard the significance of a thing as more important than its tangibility, I shall say that minds and problems are more real than cobblestones. ${ }^{39}$

If we can apply this lesson to the document, we could state that:

Thesis 5: Tacit knowledge warns us against treating the digital document as if it is only a cobblestone.

Yet this is what the open science movement does, not by introducing a new paradigm but by expanding the task assigned to the document - to document more, for example, under the FAIR principle (findable, accessible, interoperable, reusable). ${ }^{40}$ The "open notebook science engenders a new epistemic culture that is not based on the construction of 'matter of facts,' but in [what] we have called 'matter of proof'. It values the meticulous documentation of scientific practice above the making of scientific facts. ${ }^{41}$ Science, long associated with a body of facts, is now focused on the production of those facts - the creation of new knowledge rather than new knowledge alone. This seems to be a worthwhile goal, but how well it can accomplish this goal remains to be seen. If the outcome is more "matter-of-fact" science, based on more documentation (or information), and if it can provide insight into idea making - the problemfinding activity that is the work of theorizing - remains to be seen.

More fundamentally, it might be useful to attend also to what is interesting itself about the scientific enterprise that is neither "matter-of-fact" nor "matter-of-proof" as a way to think about science. An analogous issue was examined by Ronald Day in his discussion of how expertise is not based on rules (or codified knowledge) but involves the self as it fits within broader social and cultural epistemologies and the expert's use of analogical thinking. ${ }^{42}$ Fittingly, Polanyi addressed some scientific consequences of defining science with respect to the problem of problem-finding, which is based on the personal (the psychological and the epistemological). Polanyi wrote:

The declared aim of modern science is to establish a strictly detached, objective knowledge. Any falling short of this ideal is accepted only as a temporary imperfection, 
which we must aim at eliminating. But suppose that tacit thought forms an indispensable part of all knowledge, then the ideal of eliminating all personal elements of knowledge would, in effect, aim at the destruction of all knowledge. The ideal of exact science would turn out to be fundamentally misleading and possibly a source of devastating fallacies. ${ }^{43}$

Next:

It is commonplace that all research must start from a problem. Research can be successful only if the problem is good; it can be original only if the problem is original. But how can one see a problem, any problem, let alone a good and original problem? For to see a problem is to see something that is hidden. It is to have an intimation of the coherence of hitherto not comprehended particulars. ${ }^{44}$

These passages highlight an important issue in knowledge production and science that is overlooked in the open science and related literature. This is the issue of problem-finding (discovering the question to ask that might create knowledge), as opposed to problem-solving (applying the method that might produce knowledge).

We might spend so much effort on the explicit aspects of knowledge production because these acts are more tangible (like cobblestones) and because they are often the direct objects of scientific study itself. For instance, we see in current political debates, in K-12 science educational practices and so forth, a major emphasis on the analytical methods (like the simplistic scientific method often taught) that are needed to produce knowledge ${ }^{45}$ But this focus is incomplete. It is true that methodological concerns are important, and it is good that research articles contain entire sections dedicated to methodology or methods and materials. It is not clear, however, if opening up the scientific workflow will yield anymore insights into the production of knowledge, or if it will simply result in more "matter-of-fact" science.

But what about the problem-finding issue? How does someone know what research question to ask or what problems to attempt to solve? What is a good question, and how do we articulate one? This tacit dilemma arises out of our sense of the coherence of a thing or a system without necessarily being able to articulate the particulars of the thing or system. For example, if 
we become aware that we might be predicting when the electric shocks might be coming even without being able to say why or how we are aware, then we might begin to look for the particulars so that we may eventually explicate them. This awareness of the coherence of a thing marks the beginning of the ability to find an intrinsically interesting problem:

Thus the scientific interest — or scientific value — of a contribution is formed by three factors: its exactitude, its systematic importance, and the intrinsic interest of its subject matter. ${ }^{46}$

There are scientific epistemological and commensurability but also aesthetic issues that are simply not acknowledged adequately by, for instance, the open science community, which seems to largely assume that more documentation of the parts of doing science produces a stronger science alone. Pertinent to this is one basic issue: the criterion of demarcation. What criterion do we use to identify science from what is not science (or pseudoscience)? For Polanyi, if "we can know more than we can tell" entails there are limits to what we can communicate via the scholarly publishing system, and open science is about being better at communicating scientific work, then even under a better model of scholarly and scientific communication there will always be an upper bound limit on what can be falsified, verified, or reproduced via scientific documentation. This means there will never be a complete guarantee that scientific claims can be trusted via the scholarly communication system, even under a widening of that system. There is ultimately no "matter-of-proof" science, perhaps, and there will always be something intrinsic in our scientific knowing that is beyond what we can tell and that is tied to the personal activity of developing a good question to ask that arises, perhaps, out of a personal sense of coherence of a thing to study.

The aesthetic is important. Polanyi argues that science is demarcated not just by its truthfulness, its coherence, but also by whether it is interesting in the right theoretical way. This corresponds to Robert Merton's statement about the transmission of not just scientific knowing to the next generation of scientists but also of scientific taste that the "outstanding scientists" have done so well in communicating, somehow, to the next generations.

The role of outstanding scientists in influencing younger associates is repeatedly 
emphasized in the interviews with [Nobel] laureates. Almost invariably they lay great emphasis on the importance of problem-finding, not only problem-solving. They uniformly express the strong conviction that what matters most in their work is a developing sense of taste, of judgment, in seizing upon problems that are of fundamental importance. ${ }^{47}$

There is no reason to be nihilistic about what can be achieved with better scientific documentation, or by its expanded role, but tacit knowing raises interesting and serious challenges about the conduct and dissemination of (open) science, as well as any kind of knowledge that must be taught and passed from one generation to the next, from teacher to student, or from co-worker to co-worker. This is the task that Polanyi has placed before us. It is one that deals with a complicated object, the document, that if treated reductively may result in a failure to understand how we create knowledge and, as importantly, identify what kind of knowledge we find important to develop. One important question is whether the web and internet technologies that exist, ${ }^{48}$ and the type of documents involved in disseminating explicit knowhow and know-that knowledge, are embedded within a culture that welcomes treating the problem-finding dilemma with the attention it deserves.

The child still dabbles with their story about a dragon and a giant on the computer. The document is full of brightly colored text and varying font sizes. They learned how to press the enter and space bar keys repeatedly to create empty space to navigate around the page. Unsurprisingly, though, it did not take long before they became accustomed to the software. Even though the graphical metaphor still fails them on occasion, it is with less frequency; it has largely become more invisible or meaningless to them, just as did long ago for me. 


\section{Notes}

My deepest thanks to the peer reviewers and editors for helping me improve this work.

${ }^{1}$ George Lakoff, "The Contemporary Theory of Metaphor," in Metaphor and Thought, 2nd ed., ed. Andrew Ortony (Cambridge: Cambridge University Press, 1993), 202-51; William W. Gaver, "Oh What a Tangled Web We Weave: Metaphor and Mapping in Graphical Interfaces," in CHI95: Conference Companion on Human Factors in Computing Systems, Denver, CO, 1995 (New York: ACM Press, 1995), 270-71, https://doi.org/10.1145/223355.223669; Pippin Barr, Robert Biddle, and James Noble, “A Taxonomy of User-Interface Metaphors," in Proceedings of the SIGCHI-NZ Symposium on Computer-Human Interaction, Hamilton, New Zealand, 2002 (Palmerston North, NZ: The New Zealand Chapter of ACM SIGCHI, 2002), 25-30, https://doi.org/10.1145/2181216.2181221.

${ }^{2}$ Sarah Inman and David Ribes, “'Beautiful Seams': Strategic Revelations and Concealments," in CHI19: Proceedings of the 2019 CHI Conference on Human Factors in Computing Systems, Glasgow, Scotland UK (New York: Association for Computing Machinery, 2019), 1-14, https://doi.org/10.1145/3290605.3300508.

${ }^{3}$ Cynthia Taylor and Bryan M. Dewsbury, "On the Problem and Promise of Metaphor Use in Science and Science Communication," Journal of Microbiology \& Biology Education 19, no. 1 (March 30, 2018), https://doi.org/10.1128/jmbe.v19i1.1538.

${ }^{4}$ Susan Haack, Defending Science-within Reason: Between Scientism and Cynicism (Amherst, NY: Prometheus, 2007), 101.

${ }^{5}$ Cassidy R. Sugimoto and Javed Mostafa, "A Note of Concern and Context: On Careful Use of Terminologies," Journal of the Association for Information Science and Technology 69, no. 3 (2018): 347-48, https://doi.org/10.1002/asi.24014; Richard Boyd, "Metaphor and Theory Change: What Is 'Metaphor' a Metaphor For?,' in Metaphor and Thought, 2nd ed., ed. Andrew Ortony (Cambridge, UK: Cambridge University Press, 1993), 481-532.

${ }^{6}$ Nathaniel Hawthorne, "Earth's Holocaust," in Selected Tales and Sketches, ed. Michael J Colacurcio (New York: Penguin, 1987), 336-57.

${ }^{7}$ Boyd, "Metaphor and Theory Change: What Is 'Metaphor' a Metaphor For?"

${ }^{8}$ Don DeLillo, Don, White Noise (New York: Penguin Books, 1986), 92. 
${ }^{9}$ Leonard Wilcox, “Baudrillard, DeLillo's 'White Noise,' and the End of Heroic Narrative," Contemporary Literature 32, no. 3 (1991): 346-65, https://doi.org/10.2307/1208561.

${ }^{10}$ Charles Jencks, "The Post-Modern Agenda," in The Post-Modern Reader, ed. Charles Jencks (London: Academy Editions, 1992), 10-39; Martin Heidegger, John Macquarrie, and Edward Schouten Robinson, Being and Time (San Francisco: Harper and Row, 1962). See Chapter 1, Section 3, Subsection 20.

${ }^{11}$ Bryce Clayton Newell, "Crossing Lenses: Policing's New Visibility and the Role of Smartphone Journalism as a Form of Freedom-Preserving Reciprocal Surveillance," Journal of Law, Technology \& Policy 2014, no. 1 (2014): 59-104, https://heinonline.org/HOL/P?h=hein.journals/j1tp2014\&i=66; "Full Document: Trump's Call With the Ukrainian President," New York Times, September 25, 2019, sec. U.S., https://www.nytimes.com/interactive/2019/09/25/us/politics/trump-ukraine-transcript.html.

${ }^{12}$ Rebecca Solnit, The Faraway Nearby (New York, NY: Viking, 2013).

${ }^{13}$ Arnold Hauser, "The Sociological Method in Art History," in 20th Century Theories of Art, ed. James M Thompson (Ottawa: Carleton Univ. Press, 1990), 216-17.

${ }^{14}$ Rebecca Solnit, The Faraway Nearby, 90-91.

${ }^{15}$ Levy also explores the document within its environment, and in some respects, the idea of emergence, which is discussed later in this paper. David Levy, Scrolling Forward: Making Sense of Documents in the Digital Age (New York, NY: Arcade Publishing, 2001).

${ }^{16}$ Thomas M. Iiams, "Preservation of Rare Books and Manuscripts in the Huntington Library," The Library Quarterly 2, no. 4 (1932): 375-386, https://doi.org/10.1086/613158.

${ }^{17}$ Lakoff, "The Contemporary Theory of Metaphor"; Matthew G. Kirschenbaum, Mechanisms: New Media and the Forensic Imagination (Cambridge, MA: MIT Press, 2008), https://doi.org/10.7551/mitpress/7393.001.0001.

${ }^{18}$ Iiams, "Preservation of Rare Books and Manuscripts in the Huntington Library," 386; Cecilia Bembibre and Matija Strlič, "Smell of Heritage: A Framework for the Identification, Analysis and Archival of Historic Odours," Heritage Science 5, no. 1 (December 2017): 1-11, https://doi.org/10.1186/s40494-016-0114-1.

${ }^{19}$ Walter J. Ong, Orality and Literacy: The Technologizing of the Word, 2nd ed. (London: 
Routledge, 1982), http://www.worldcat.org/isbn/0415281288.

${ }^{20}$ Walter J. Ong, The Presence of the Word: Some Prolegomena for Cultural and Religious History (Binghamton, NY: Global Publications, 2005); David Suda, The Moving Image: Immutability, Metaphors, and the Time Clocks Tell (Lanham, MD: University Press of America, 1989).

${ }^{21}$ Larry McMurtry, “On Rereading,” The New York Review of Books, July 14, 2005, https://www.nybooks.com/articles/2005/07/14/on-rereading/.

${ }^{22}$ Fred Dretske, "Epistemic Operators," in Epistemology: An Anthology, 2nd ed., eds. Ernest Sosa et al., (Malden, MA: Wiley-Blackwell, 2008), 237-246.

23 Jonathan Jenkins Ichikawa and Matthias Steup, “The Analysis of Knowledge," in The Stanford Encyclopedia of Philosophy, Summer 2018 ed., ed. Edward N. Zalta (Stanford, CA: Metaphysics Research Lab, 2018), https://plato.stanford.edu/archives/sum2018/entries/knowledge-analysis/.

${ }^{24}$ Anne Clinio and Sarita Albagli, "Open Notebook Science as an Emerging Epistemic Culture within the Open Science Movement," Revue Française Des Sciences de l'Information et de La Communication, no. 11 (August 1, 2017), https://doi.org/10.4000/rfsic.3186.

${ }^{25}$ J. Scott Long, The Workflow of Data Analysis: Using Data (College Station, TX: Stata Press, 2009).

${ }^{26}$ Vladimir B. Teif, “On the Sociology of Science 2.0," in Opening Science: The Evolving Guide on How the Internet Is Changing Research, Collaboration and Scholarly Publishing, eds. Sönke Bartling and Sascha Friesike (Cham, CH: Springer International Publishing, 2014), 309 11, https://doi.org/10.1007/978-3-319-00026-8_23; Center for Open Science, "Center for Open Science," accessed May 27, 2020, https://www.cos.io.

${ }^{27}$ Michael Polanyi, The Tacit Dimension (Chicago: University of Chicago Press, 2009), 4, http://www.worldcat.org/oclc/ 948248420.

${ }^{28}$ David Ribes, "How I Learned What a Domain Was," Proceedings of the ACM on Human-Computer Interaction 3, no. CSCW (November 7, 2019): 38:1-38:12, https://doi.org/10.1145/3359140; David Ribes and Geoffrey C. Bowker, "Between Meaning and Machine: Learning to Represent the Knowledge of Communities," Information and Organization 
19, no. 4 (October 1, 2009): 199-217, https://doi.org/10.1016/j.infoandorg.2009.04.001.

${ }^{29}$ Nonaka was one of the first researchers to begin categorizing the differences between tacit and explicit knowledge. Ikujiro Nonaka, "A Dynamic Theory of Organizational Knowledge Creation,” Organization Science 5, no. 1 (1994): 14-37, https://doi.org/10.1287/orsc.5.1.14.

${ }^{30}$ T. D. Wilson, "The Nonsense of 'Knowledge Management'," Information Research 8, no. 1 (2002), accessed July 31, 2020, http://informationr.net/ir/8-1/paper144.html.

${ }^{31}$ Alex Csiszar, "Peer Review: Troubled from the Start," Nature News 532, no. 7599 (April 21, 2016): 306, https://doi.org/10.1038/532306a; The communism norm reflects this epistemological issue in particular, at least as it focuses on findings more so. Robert K. Merton, "The Normative Structure of Science," in The Sociology of Science: Theoretical and Empirical Investigations, ed. Norman W. Storer (Chicago: University of Chicago Press, 1973), 267-78.

${ }^{32}$ Paul Dourish, "Not The Internet, but This Internet: How Othernets Illuminate Our Feudal Internet," Aarhus Series on Human Centered Computing 1, no. 1 (2015): 157-168, https://doi.org/10.7146/aahcc.v1i1.21200; Bruno Latour, Science in Action: How to Follow Scientists and Engineers through Society (Cambridge, MA.: Harvard University Press, 1987), 4.

${ }^{33}$ Clinio and Albagli, "Open Notebook Science as an Emerging Epistemic Culture within the Open Science Movement."

${ }^{34}$ Edmund L. Gettier, "Is Justified True Belief Knowledge?," Analysis 23, no. 6 (June 1, 1963): 121-23, https://doi.org/10.1093/analys/23.6.121.

${ }^{35}$ Haack, Defending Science-within Reason, 95.

${ }^{36}$ David Fischer et al., "A Human Brain Network Linking Arousal to Awareness (S35.004)," Neurology 86, no. 16 Supplement (April 5, 2016), https://n.neurology.org/content/86/16_Supplement/S35.004.

${ }^{37}$ C. Sean Burns, "Academic Libraries and Automation: A Historical Reflection on Ralph Halstead Parker," Portal: Libraries and the Academy 14, no. 1 (2014): 87-102, http://muse.jhu.edu/journals/portal_libraries_and_the_academy/v014/14.1.burns.html.

${ }^{38}$ Kenneth J. Berry and Thomas W. Martin, "The Synecdochic Fallacy: A Challenge to Recent Research and Theory-Building in Sociology," The Pacific Sociological Review 17, no. 2 (1974): 139-66, https://doi.org/10.2307/1388339. 
${ }^{39}$ Polanyi, The Tacit Dimension, 32-33.

${ }^{40}$ National Academies of Sciences, Engineering, and Medicine, "Introduction," Open Science by Design: Realizing a Vision for 21st Century Research (Washington, DC: National Academies Press, 2018), https://www.ncbi.nlm.nih.gov/books/NBK525422/.

${ }^{41}$ Clinio and Albagli, "Open Notebook Science as an Emerging Epistemic Culture within the Open Science Movement."

${ }^{42}$ Ronald E. Day, “Clearing up 'Implicit Knowledge': Implications for Knowledge Management, Information Science, Psychology, and Social Epistemology," Journal of the American Society for Information Science and Technology 56, no. 6 (April 1, 2005): 630-35, https://doi.org/10.1002/asi.20153.

${ }^{43}$ Polanyi, The Tacit Dimension, 20.

${ }^{44}$ Polanyi, 21.

${ }^{45}$ James Blachowicz, "How Science Textbooks Treat Scientific Method: A Philosopher's Perspective," The British Journal for the Philosophy of Science 60, no. 2 (June 1, 2009): 303-44, https://doi.org/10.1093/bjps/axp011.

${ }^{46}$ Polanyi, The Tacit Dimension, 66.

${ }^{47}$ Robert K Merton, "The Matthew Effect in Science," in The Sociology of Science: Theoretical and Empirical Investigations, ed. Norman W Storer (Chicago: University of Chicago Press, 1973), 439-59.

${ }^{48}$ Dourish, "Not The Internet, but This Internet," 167. 